\title{
Liposuction in Gynecomastia: An Institutional Experience
}

\author{
Jyoti Rayamajhi, Sushil Rawal and Srijan Malla
}

Department of surgery; Nepalese Army Institute of Health Sciences, Shree Birendra Hospital, Chhauni, Kathmandu, Nepal.

\begin{abstract}
Introduction: Gynecomastia is a benign condition of the male breast with glandular tissue proliferation. It can be physiologic or pathologic and many a times manifestation of underlying chronic pathology. Its treatment is selected based on cause, age and grade with surgical or pharmacological modalities. Periareolar incision with liposuction is the choice for higher grade gynecomastia.

Methods: Patients record of Gynecomastia undergoing surgery for last two years from a tertiary hospital was reviewed retrospectively. Detailed clinical evaluation and appropriate investigations were obtained from medical records. Patients with chronic liver and renal disease, hyperthyroidism, alcoholics and patients on medical treatment as anabolic steroids were excluded from the study. Treatment of gynecomastia and its outcome was recorded and entered in excel data sheet and analyzed.

Results: Among 33 patients enrolled, 19 had unilateral gynecomastia whereas 14 patients had bilateral gynecomastia. Of them 10 were of Simons grade I, 17 of IIA and 6 of IIB. Among operated patients mean age was 53.24 years.

Conclusion: Periareolar incision with liposuction is the treatment of patient choice for higher gynecomastia due to its better outcome in terms of complication and patient satisfaction.
\end{abstract}

Correspondence: Jyoti Rayamajhi, Department of Surgery, Nepalese Army Institute of Health Sciences, Shree Birendra Hospital, Chhauni, Kathmandu, Nepal. Email: jyoti.20091@hotmail.com

To cite this article: Rayamajhi J, Rawal S, Malla S. Liposuction in Gynecomastia: An Institutional Experience. Medical Journal of Shree Birendra Hospital. 2017;17(2):37-40.

DOI: http://dx.doi.org/10.3126/mjsbh.v16i2.17856

\section{Conflict of Interest: None declared}




\section{INTRODUCTION}

Gynecomastia is a benign condition affecting about one third of total male population and is proliferation of glandular tissue of the male breast. Pseudo-gynecomastia may be confused with gynecomastia and must be distinguished.1-4 Gynecomastia is distressing condition of all ages males. Usually causes of gynecomastia are benign and self-limited.2,5 Gynecomastia can be physiologic or pathologic. Physiologic one is seen in newborns, pubertal male, and elderly male. Pathologic gynecomastia is manifestation of underlying chronic conditions or use of drugs. $3,4-6$

Based on patient factor and grade, gynecomastia can be treated by surgical or pharmacological modalities. Surgical excision of breast glands with liposuction is the option of choice with low complications rate. Gynecomastia at puberty can be managed safely with anti-oestrogen therapy. ${ }^{1}$ There is high patients and surgeons' satisfaction score and excellent aesthetic results following periareolar incision with liposuction which can be power or ultrasonic assisted (PAL or UAL) for higher grade gynecomastia in comparison with conventional breast reduction surgeries. ${ }^{7-13}$

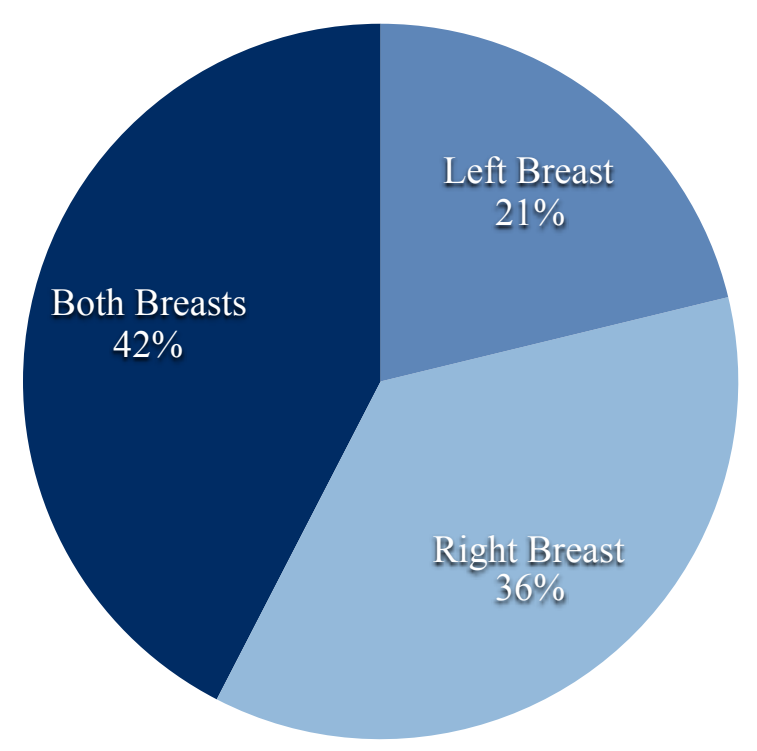

Figure 1. Site of gynecomastia
As liposuction is rarely done in Nepal and only two case reports being published in our country so far, we want to share ${ }^{14}$ our institutional experience of last two years on liposuction for gynecomastia in male.

\section{METHODS}

We have retrospectively reviewed and analyzed the records of the patients undergoing gynecomastia surgery for last two years in our hospital. All the patients had undergone detailed clinical evaluation and appropriate investigations after admission. Information regarding age of onset, etiology, laterality, nipple discharge was collected from patient's medical records. Based on the clinical evaluation and investigations, secondary causes of gynecomastia were ruled out prior to surgical management of the case. Patients with chronic liver disease, renal disease, hyperthyroidism, alcoholics and patients on medical treatment as anabolic steroids were excluded from the study. Among those who met the eligibility criteria, the grade of gynecomastia, the presence of skin excess, causative factors, duration of symptoms and surgical procedure and complications were recorded. The patient information was entered in excel data sheet and analyzed.

\section{RESULTS}

In this retrospective study, a total of 33 patients presented to Department of Surgery at our institution over the study period and met the eligibility criteria were included. 19 of 32 patients (59.37\%) had unilateral gynecomastia whereas 14 patients $(40.62 \%)$ had bilateral gynecomastia. Among unilateral, right breast only was affected in 12 and left breast only in 7 cases (Fig.1). The mean age of patients was $53.24 \pm 15.266$ Years with range from 26-69 years. Among 33 cases, 10 $(30.30 \%)$ were having Simons grade I disease, 17 (51.51\%) grade IIA and 6 (18.18) grade IIB disease. 
Table 1: Patient Satisfaction

\begin{tabular}{|l|r|r|}
\hline & Frequency & Percent \\
\hline $\begin{array}{l}\text { Lost follow- } \\
\text { up }\end{array}$ & 2 & 6.1 \\
\hline Excellent & 21 & 63.6 \\
\hline Good & 2 & 6.1 \\
\hline Poor & 3 & 9.1 \\
\hline Satisfactory & 5 & 15.2 \\
\hline Total & 33 & 100.0 \\
\hline
\end{tabular}

Following procedure, as acute complications, three seroma, one hematoma, one wound dehiscence occurred. Later in one case there was irregularity of breast. Thus, total six cases had some complications and all were addressed appropriately. Among total operated cases two lost the follow-up. In outcome, majority of the patients (63.6\%) responded as excellent patient satisfaction rate.

\section{DISCUSSION}

In recent times management of the gynecomastia is revolutionized with introduction of new techniques to reduce the breast tissue. Recent studies stress on liposuction as a management modality for gynecomastia as it has less complications and better patient's satisfaction. ${ }^{1,8-13}$ Fagerlund et al. in a review article compared traditional surgical excision of breast glandular tissue with liposuction and concluded that liposuction provides good results with low complication rates. ${ }^{1}$ In our series most of the patients were elderly male with mean age of $53.24 \pm 15.266$ years. In contradiction to similar studies by Lee et. al. and Li et.al. where the mean age was 21.5 years and 27 years respectively, we had relatively older patients. ${ }^{12,13}$ More than two thirds cases were of Simons grade IIA. The higher grade gynaecomastia in this series may be explained by the fact that the patients with relatively larger sized gynaecomastia may have been compelled to seek medical attention and the patients with lower grade may have not come for medical attention.

Though there were six cases with complications, the complications were minor ones and managed adequately. Overall patient satisfaction was excellent as shown by other studies. ${ }^{13}$ The major limitation of our study is the small number of patients enrolled in this single centric study.

\section{CONCLUSION}

Periareolar incision with liposuction is the treatment of patient choice for higher grade gynecomastia due to its better outcome in terms of complications and patient satisfaction.

\section{REFERENCES}

1. Fagerlund A, Lewin R, Rufolo G, Elander A, Santanelli di Pompeo F, Selvaggi G. Gynecomastia: A systematic review. Journal of plastic surgery and hand surgery. 2015 Nov 2;49(6):311-8.

\section{DOI: 10.3109/2000656X.2015.1053398}

2. Carlson HE. Gynecomastia. In2015 Meet-The-Professor: Endocrine Case Management 2015 (pp. 289-292). The Endocrine Society.

3. Braunstein GD. Gynecomastia. New England Journal of Medicine. 1993 Feb 18;328(7):490-5.

4. Hernández-Pérez E, Khawaja HA, Seijo-Cortes JA. Liposuction for Gynecomastia. InLiposuction 2006 (pp. 460-464). Springer Berlin Heidelberg. 
5. Carlson HE. Approach to the patient with gynecomastia. The Journal of Clinical Endocrinology \& Metabolism. 2011 Jan;96(1):15-21.

DOI: $10.1210 /$ jc.2010-1720

6. Dickson G. Gynecomastia. American family physician. 2012 Apr 1;85(7) :716-722. URL: http:// familydoctor.org/080.xm1.

7. Taheri AR, Farahvash MR, Fathi HR, Ghanbarzadeh K, Faridniya B. The Satisfaction Rate among Patients and Surgeons after Periareolar Surgical Approach to Gynecomastia along with Liposuction. World J Plast Surg 2016;5(3):287-292.

8. Schroeder L, Rudlowski C, Walgenbach-Bruenagel G, Leutner C, Kuhn W, Walgenbach KJ. Surgical strategies in the treatment of gynecomastia grade I-II: The combination of liposuction and subcutaneous mastectomy provides excellent patient outcome and satisfaction. Breast Care. 2015 Apr 9;10(3):184-8. DOI: $10.1159 / 000381152$

9. Song YN, Wang YB, Huang R, He XG, Zhang JF, Zhang GQ, Ren YL, Pang JH, Pang D. Surgical treatment of gynecomastia: mastectomy compared to liposuction technique. Annals of plastic surgery. 2014 Sep 1;73(3):275-8.

\section{DOI: 10.1097/SAP.0b013e31827c7949}

10. Wong KY, Malata CM. Conventional versus ultrasound-assisted liposuction in gynaecomastia surgery: a 13-year review. Journal of Plastic, Reconstructive \& Aesthetic Surgery. 2014 Jul 31;67(7):921-6.

DOI: http://dx.doi.org/10.1016/j.bjps.2014.03.004

11. Sarkar A, Bain J, Bhattacharya D, Sawarappa R, Munian K, Dutta G, Naiyer GJ, Ahmad S. Role of combined circumareolar skin excision and liposuction in management of high grade gynaecomastia. $\mathrm{J}$ Cutan Aesthet Surg 2014;7:112-116. URL: http://www.jcasonline.com/text.asp?2014/7/2/112/138354

12. Lee JH, Kim IK, Kim TG, Kim YH. Surgical correction of gynecomastia with minimal scarring. Aesthetic plastic surgery. 2012 Dec 1;36(6):1302-6.

DOI:10.1007/s00266-012-9970-6

13. Li CC, Fu JP, Chang SC, Chen TM, Chen SG. Surgical treatment of gynecomastia: complications and outcomes. Annals of plastic surgery. 2012 Nov 1;69(5):510-5.

14. Lohani I, Shrestha JM. Liposuction for diffuse gynaecomastia. Journal of Institute of Medicine. 2006;28(1):72-3. 